\title{
INTERNATIONAL COOPERATION AS A PREREQUISITE FOR IMPROVEMENT OF ACCESS TO ORPHAN BIOLOGIC MEdiCINES
}

Accepted
04. 07. 2021
Revised
09. 09. 2021
Published
29. 10. 2021

Keywords biologic medicinal product, orphan drugs, biologics, rare diseases, biosimilars

\section{Zbigniew Więckowski}

Cardinal Stephan Wyszynski University in Warsaw, Law and Administration Faculty, Institute of Legal Studies UKSW, Warsaw, Poland.

E-mail: z.wieckowski@uksw.edu.pl

CORRESPONDING AUTHOR

z.wieckowski@uksw.edu.pl

Abstract Rare diseases constitute a global problem. Worldwide, 350 million people suffer from such diseases. The number of diagnosed cases are on the rise. Only a small percentage of those suffering have the opportunity to be treated with modern therapies. Medicines used to treat rare diseases are called orphan drugs. Biologic medicines developed for orphan drug indications, besides patent protection, have a period of regulatory and market exclusivity. After this period of time has elapsed, access to orphan drugs could be improved by the introduction of biosimilar medicines. The biggest challenge is to develop effective legal, tax and economic incentives to stimulate the development of biosimilar medicines for orphan indications. The regulatory agencies EMA in the EU and the FDA in the USA - play a key role in increasing access to orphan biologics. Undoubtedly, the international cooperation, especially the mutual recognition of registration procedures between countries, and the creation of a common vocabulary and the unification of incentives for the pharmaceutical industry would have the positive impact on access to modern therapies. 


\section{$1 \quad$ Introduction}

Rare diseases constitute a global problem. Worldwide, 350 million people suffer from such diseases (Klimova et al., 2017), including 25-30 million in the US (Stoller, 2018) and 30 million in the EU (European Commission, n.d.). Unfortunately, the number of diagnosed cases are on the rise. About 80 percent of rare diseases have a genetic basis (Liu et al., 2019), while the remaining 20 percent may be linked to infection, allergy or environmental factors (Slade et al., 2018). More than half of rare diseases emerge during childhood. Rare diseases cause more than 30 percent of hospital admissions in children's hospitals and account for 40 to 45 percent of deaths before the age of 15 (Gunne et al., 2020). Currently, only a small percentage of those suffering from rare diseases have the opportunity to be treated with modern (biologic or gene) therapies (Maldonado et al., 2021).

The current pandemic has exacerbated problems for people with rare diseases, as they are among the most vulnerable to COVID-19 (Chowdhury, Al Sium \& Anwar, 2021; EURORDIS, 2020).

There is no single, universally accepted definition of a rare disease (Richter et al., 2015). According to Regulation No 141/2000 of the European Parliament and of the Council of 16 December 1999 on orphan medicinal products (EUR-Lex, n.d.), a rare disease is a disease with a prevalence of no more than five per 10.000. The official definition of an ultra-rare disease was adopted by the European Union in Regulation No 536/2014 of the European Parliament and of the Council of 16 April 2014 (EUR-Lex, n.d.). It indicates that an ultra-rare disease is a disease with an average incidence of no more than one in 50.000 people. In the US, any disease affecting fewer than 200.000 people is considered rare (usually 7.5 cases per 10,000 persons). The definition comes from the Orphan Drug Act of 1983 (e-CFR, n.d.).

Medicines used to treat rare diseases are called orphan drugs (European Medicines Agency, n.d.). The term 'orphan drug' is derived from the fact that pharmaceutical companies were not interested in developing such drugs due to the lack of financial incentives (the development of orphan drugs is done also in the public, non-profit institutions, for example: The Cancer Research UK Cancer Therapeutics Unit at The Institute of Cancer Research, London, the Institute for Applied Cancer Science at MDAnderson Cancer Center, see more: Workman, Draetta, Schellens, Bernards, 
2017). Many countries have introduced incentives and financial assistance to promote the development of therapies for orphan drugs. In terms of financial incentives, exemptions from various types of administrative fees are the most frequent. Tax incentives are less common, but also occur. Non-financial incentives are most common: patient access to therapy under 'compassionate use', administrative advice, special reimbursement procedure rules (DZP, PEX PharmaSequence, 2020). In terms of reimbursement proceedings involving orphan products, the range of methods employed is extremely wide. In Belgium and Slovakia, for example, it is possible to be exempted from having to provide a pharmacoeconomic assessment. In Bulgaria, Sweden, Romania and the Netherlands, multi-criteria analysis (MCA) is used in health technology assessment (HTA). In the Czech Republic, reimbursement is proposed for a transitional period. In France, orphan products benefit from an accelerated assessment process. In Germany, there is an exemption from proving therapeutic benefit if the cost of the therapy does not exceed a certain level (DZP, PEX PharmaSequence, 2020).

The largest and clinically most effective group of orphan drugs are biologic medicines such as monoclonal antibodies, vaccines and blood clotting factors. In recent years, biologic drugs have revolutionised treatment in many therapeutic areas (Świerczyński \& Więckowski, 2019; 2020). They are used primarily in the fields of dermatology and oncology and to treat rheumatic disease. During the past year, significant progress was made in the development of therapies for rare diseases in the USA when the Food and Drug Administration (FDA) authorised 32 new drugs and biologics with orphan drug designation (Food and Drug Administration, 2021).

The overall regulation of biologic medicines is well-established and does not require wide-scale changes. Biologic medicines developed for orphan drug indications, besides the patent protection, have a period of regulatory and market exclusivity. After this period of time has elapsed, access to orphan drugs could be improved by the introduction of biosimilar medicines (Dowlat, 2016). The biggest challenge is to develop effective legal, tax and economic incentives to stimulate the development of biosimilar medicines for orphan indications. Without competition from biosimilar medicines there is a risk that the original product will continue to monopolize the market. This leads to the maintenance of high prices (Moon, 2017; World Health Organization, 2018) and makes biologic orphan products relatively expensive, and out of the reach of poorer nations and populations (Chan et. al., 2020; Miller \& 
Lanthier, 2018). Among numerous hurdles limiting the availability of biosimilar medicines for orphan indications is a long clinical development pathway, similar to that of the original medicine. One of the major problems is that, most likely due to lack of sufficient economic incentives, most orphan products do not have generic, possibly biosimilar, equivalents. There is a biosimilar version for orphan biological molecules in clinical development in only eleven percent of the cases, compared to 23 percent of all biological drugs (Bruce, 2021).

The first step to increase patient access to orphan medicines is to propose a coherent legal model for them. Proposed legal solutions need to be internationally acceptable due to the specificity of rare diseases and the limited number of patients at the national level.

Because of its pioneering approach to the subject, the international perspective initially should be limited to the US and EU. These regions not only have the greatest market potential, but also the greatest level of legislative advancement to date. The regulatory agencies - the European Medicines Agency (EMA) in the EU and the FDA in the US - play a key role in increasing access to orphan biologics. Undoubtedly, both the mutual recognition of registration procedures between the EU and the US, and the creation of a common vocabulary and the unification of incentives for the pharmaceutical industry would have an impact on access to modern therapies. At present, the legal basis, regulatory pathways and approval requirements for orphan and biosimilar biological drugs in the US and the EU are very different.

Cooperation between the EMA and the FDA formally began in 2003. Currently, the agencies maintain almost daily contact. The cooperation takes place mainly through working groups called "clusters" (Teixeira, Kweder \& Saint-Raymond, 2020; European Medicines Agency, n.d.).

The EMA-FDA cooperation on orphan drugs has been ongoing since 2008 and mainly concerns orphan drug designation, product development proposals, administrative simplification, exchange of opinions, drafting of guidance documents, as well as opportunities for collaboration at conferences and workshops. 
The primary successes of the cluster have included the development of common procedures for the submission of applications for orphan drug designation and annual reporting on the status of development of designated orphan drugs.

For example, in June 2020, officials from the European Commission (EC - DG SANTE), EMA and FDA held a bilateral regulatory dialogue meeting. The meeting reviewed current joint initiatives, discussed strategic priorities for the coming years and identified areas where cooperation can be further strengthened. Among the various topics discussed were orphan and paediatric medicines. Officials shared information on the initiatives being undertaken by each agency and discussed possible collaboration on data analysis to characterise rare diseases (European Medicines Agency, 2020).

The initiatives cited above are examples of cooperation based largely on the exchange of opinions, experience and information between the two agencies. There is no doubt that, in order to effectively improve the availability of orphan biologicals, it is necessary not only to have greater institutional cooperation but, above all, to have mutual recognition and far-reaching harmonisation of rules. From the perspective of patients suffering from rare diseases, the optimal solution would be to reject the primacy of national jurisdictions in favour of supra-state structures. An international consensus is therefore required and an international convention must be adopted which could provide a framework for potential cooperation.

The paper is divided into four parts. In the first, I present the current state of the art on orphan medicines from the American and the EU legislation perspective. The second section examines the most frequently identified problems that prevent unrestricted access to orphan biological drug therapies. The third section provides arguments in favour of the importance of international cooperation on the subject of orphan biologics. The paper ends with a summary and conclusions. 


\section{Orphan medicines - American and the EU legislation - state of the art}

The US was the first country in the world to address the issue of orphan drugs (Orphan Drug Act, 1983 "ODA"). Since the passing of the ODA, more than 950 orphan drugs and biologics have been approved in the US, compared with ten in the previous decade. The US model was followed in subsequent years by Japan (Sakushima, Takeda \& Aoi, 2021) the EU and Australia (Neelakandan, Venkatesh \& Gomez, 2019). Japan (Orphan Drug Act, 1993) and Australia (Orphan Drug Program, 1997) were the next countries to introduce a definition of a rare disease in their legal system. These definitions stated that a rare disease is a disease that affects fewer than 40 (in the case of Japan) and 11 (in the case of Australia) patients per 100.000 people. The US regulations have thus become a starting reference for regulations emerging in other jurisdictions. Despite the many initiatives taken by EU institutions in recent years to ensure greater access to orphan drugs, the US still dominates this area (National Organization for Rare Disorders, 2021).

In the EU, rare diseases received their special status after the adoption in 2001 of legislation on medicines for rare diseases and in 2006 the regulation on medicines for children. For the period of May-July 2021, the European Commission launched an open public consultation on the revision of the rules on medicines for children and rare diseases. The consultation follows an evaluation of the existing rules published in the summer 2020. While the evaluation confirmed that the legislation stimulates research and development for medicines to treat children and rare diseases, it also revealed some shortcomings in the current system, primarily concerning the development of medicines in areas of high unmet patient demand and their availability to all patients in all Member States (European Commission, 2021).

Thanks to the work undertaken on amending current EU legislation, there is a chance of improving access to modern therapies. The issue of orphan medicinal products is high on the European Commission's agenda, as is improving the greater availability and affordability of medicines. At the same time, the European Commission is currently developing its pharmaceutical and intellectual property strategy. Julie Maréchal-Jamil from Medicines for Europe is right saying: "How we prioritize the shaping of an environment favorable to off-patent competition in this 
space will condition the landscape in the next decade. We foresee that the EU framework currently in the making will help significantly grow the proportion of biosimilar medicines available in orphan indications" (Bruce, 2021).

This is an important time to propose greater international cooperation as the biologics legal pathway is unlikely to change markedly and research into orphan biologic medicines is at a crucial point. The first biologic orphan medicines registered in the EU will lose patent protection in the next few years (some 28 biologic orphan medicines will be eligible for competition by 2028) and the methods by which biosimilar orphan medicines will gain access to the market are yet to be shaped (Bruce, 2021).

The EMA has highlighted the benefits of international cooperation. The EMA shares its experience in the regulation of biosimilar medicinal products with member state agencies as well as other regulatory bodies from other parts of the world. At the same time, the EMA points to a fundamental problem that represents a significant barrier to improving access to modern therapies, including orphan biologics: "[it] is difficult because different legal and regulatory frameworks are applicable in each country and govern the development and approval of biosimilar medicines across the world" (Bruce, 2021).

The revision of EU legislation and the unprecedented international cooperation in the fight against the COVID-19 pandemic provides hope that now is the best time to launch an international initiative on rare diseases. A strategy of limiting itself to individual nation states does not serve the cause. An important example of a comprehensive multilateral agreement reached through international consensus is the WHO Agreement on Trade-Related Aspects of Intellectual Property Rights (TRIPS), which established minimum requirements for patent protection (Athreye, Piscitello \& Shadlen, 2020). TRIPS shows that through consensus-building, and where there is will to do so, the international community can agree on issues affecting humanity at the global level. 


\section{$3 \quad$ Problems to be solved}

The concept of reaching international consensus on stimulating access to modern therapies could be a part of the worldwide debate on the future of law for biologic orphan drugs. The most frequently identified problems that prevent unrestricted access to orphan biological drug therapies include:

a) the lack of sufficient incentives to conduct drug trials involving a limited patient population (including tax incentives) (Day et al., 2018);

b) short periods of data exclusivity and market exclusivity (Sarpatwari et al., 2018);

c) the difficulty of properly identifying patients for clinical trials (Gaasterland et al., 2019);

d) the limited number of clinical sites with sufficient experience to conduct trials for a given disease (Gelinas, Crawford, Kelman \& Bierer, 2019);

e) long clinical development pathways for orphan biosimilars that differ little from that of the originator drug;

f) inefficient reimbursement (Czech, 2019);

g) g)lack of clear regulation on automatic substitution (Afzali, Furtner, Melsheimer \& Molloy, 2021);

h) lack of unified terminology in the field of biologics;

i) limited market size and associated difficulties for the potential emergence of biosimilar medicines.

A further consideration is patents, which are often one of the main barriers to the marketing of all alternative pharmaceuticals such as 'me-too' medicines, biosimilars and generics. In the context of patent law, two basic questions concerning biologic orphan drugs arise:

1) should this kind of invention be treated as common good (part of the public domain)?

2) what is the optimal regime of intellectual property protection for orphan biologics? 
Proposed changes could include modifications, such as creating a subtype of patent, a sui generis protection of genetic components of biological drugs and strengthening the rules on business confidentiality (Świerczyński \& Więckowski, 2019a).

A problem associated with the increased availability of orphan biologics is one that is often overlooked: patient loyalty to the drug. This is often a consequence of the so-called "diagnostic odyssey" that patients with rare diseases experience. It frequently takes months, and sometimes years, of research to find the cause of patients' conditions. Patients who successfully finished an "odyssey" during the lengthy diagnostic process often become extremely loyal to a drug. The same is true for medical specialists, who develop a bond of loyalty by working with the responsible parties, possibly the drug manufacturers. This should not come as a surprise, especially as doctors themselves often encourage manufacturers to continue research and support them in passing on the necessary knowledge (IQVIA, 2020).

\section{$4 \quad$ Importance of cooperation}

The legal model for orphan biologic medicines will fulfil its function if it is created and accepted by the international community. The development of the legal model is important because:

1) a transparent and reliable legal model for orphan biologics is a necessary condition for the successful development of health care systems as a whole at a time when there is an increasing global prevalence of rare diseases;

2) orphan biologic medicines drive up the cost of healthcare; indeed, orphan biologics have been called "niche-busters" as they consume a significant part of health budgets because of their extremely high cost;

3) the observation of the changes currently taking place in the field of access to vaccines against COVID-19 to provide a global solution within a short time-span leads to the conclusion that significant changes are required also in the regulation of orphan biologics. Access to modern therapies should not be restricted. It is a global goal to make them widely accessible in thirdworld countries, which have no specific orphan biologic medicines legislation, and where the majority of patients can neither access nor afford modern therapies (Kontoghiorghe et al., 2014); 
4) the dynamic development of the market for biosimilar drugs in recent years is related to the expiration of the exclusive rights (data exclusivity and market exclusivity) of reference orphan biologic products. As biologics are increasingly approved with data from post-authorization and real-world evidence, there are questions related to the accessibility of this data once exclusivities have expired;

5) the expiration of patents relates to orphan biologic medicines that are highly profitable blockbuster drugs. It is advisable to make in-depth analysis on the need to prepare legal regulations dedicated to biosimilar medicinal products, especially since manufacturers of innovative orphan biologics expect many incentives for their development. This leaves the important question of what would be needed to support necessary biosimilar competition in this field;

6) the introduction of orphan biosimilar products has the potential to reduce healthcare costs, generating significant savings and better patient access to rare disease medicines;

7) it can lead to changes to regulatory law governing clinical trials, assisting market development of orphan biosimilar drugs and access to patients;

8) the automatic substitution (practice at pharmacy level of dispensing one medicine instead of appropriate another without consulting the prescriber) has the potential to enhance access to biologic therapies. The key issue is to determine whether patient safety concerns can be countered with an increased availability of medicines;

9) of the development of telemedicine and e-health platforms. Health care systems are currently undergoing significant changes due to the rapid development of information technology including use of artificial intelligence and developments introduced during the COVID-19 pandemic crisis. Developers of orphan biologics identified one of the significant hurdles they face as the identification of patients for trial recruitment. It is almost impossible to find the required number of patients within a reasonable time period. Changes in technology may lead to increased availability of orphan biologic medicines, mainly through the support of the qualification process for the biological treatment of patients (Schaefer et al., 2020). 
Many of the problems cited above could be avoided if international action were taken. Certainly, an immediate priority is to harmonise: a) the regulation of orphan drugs and b) periods of data and market exclusivity. Secondly, it is important to develop globally applicable incentives for the manufacture of biosimilar orphan products. There needs to be international consensus on this. This seems difficult, but not impossible, as the example of the TRIPS Agreement demonstrates.

The only way to improve access to biological treatments for rare diseases is through not only international cooperation but also the joint development of rules and regulations. Only a global approach to the problem can bring about significant change.

There is no shortage of examples of international cooperation in expanding access to therapies for rare diseases. A few include:

The International Rare Diseases Research Consortium (IRDiRC) - brings together national and international organisations (governmental and non-profit), pharmaceutical and biotechnology companies, patient organisations and researchers to promote international collaboration and the development of research on rare diseases worldwide. It brings together entities from Africa, Asia, Australia, North America and Europe (IRDiRC, n.d.).

EURORDIS-Rare Diseases Europe - a non-profit organisation of 962 rare disease patient organisations from 73 countries (EURORDIS, n.d.).

The European Joint Programme on Rare Diseases (EJP RD) - brings together more than 130 institutions from 35 countries: 26 EU Member States (Austria, Belgium, Bulgaria, Czech Republic, Denmark, Estonia, Finland, France, Germany, Greece, Hungary, Ireland, Italy, Latvia, Lithuania, Luxembourg, Malta, Netherlands, Poland, Portugal, Romania, Sweden, Slovakia, Slovenia, Spain) seven associated countries (Armenia, Georgia, Israel, Norway, Serbia, Switzerland, Turkey), UK and Canada (EJP RD, n.d.). 
All these initiatives substantiate the need for international cooperation. So far, however, the dominant model of cooperation has been the non-governmental one, at the level of, above all, patient organisations and non-profit institutions. Although initiatives of this kind are extremely valuable, standing alone they are insufficient. Action must be taken that will result in the adoption of specific legal regulations. Only the global approach will markedly improve access to modern forms of therapy, including biological or gene therapies. The current model, which is based solely on calculations involving individual national markets, is ineffective and often perpetuates monopolistic models in the area of access to medicines. A supranational agreement is required, for example, within the European Union, and uniform rules are needed for access to medicines used to treat rare diseases. The experience of the European Commission's negotiations with the responsible entities supplying the COVID-19 vaccine shows that, after the necessary adjustments (failure of the AstraZeneca agreement), joint EU purchases of medicines to treat rare diseases are possible.

\section{$5 \quad$ Conclusions}

Plans for international cooperation in the area of providing wider access to biologic orphan products requires specific tasks to be undertaken. Medicines for Europe has proposed the following, with which I fully concur:

1) Introduction of regulatory incentives to support the development of products developed after the expiry of patent protection for the original product, reflecting the incentives and facilities available to manufacturers of innovative products.

2) The adoption of a streamlined approach to the development of biosimilar medicinal products, in particular with regard to clinical comparability (nonmandatory).

3) The need to ensure conditions for the global development of orphan biosimilars.

4) Reducing time limits for pricing and reimbursement decisions on orphan products. This would ensure that biosimilars can be brought to market as soon as the regulatory and intellectual property exclusivity for orphan originator products expires. 
5) Pricing and reimbursement conditions should be tailored to the specificities of orphan biosimilars. The current rules are not fit for purpose and do not allow responsible entities to obtain a sufficient return on their investment (Bruce, 2021).

Although it may seem difficult to establish rules for satisfactory cooperation between multiple parties, there seems to be no better solution than to work together internationally to improve access to orphan biologic products.

\section{Note}

This article was written due to the performance of the scientific research project no. 2017/25/N/HS5/01505 titled: Legal model of biosimilars financed by the National Scientific Center.

\section{Legislation, Acts, Regulations and Court Decisions}

DZP, PEX PharmaSequence (2020) Choroby rzadkie dostępność terapii: przegląd rozwiązań i rekomendacje dla Polski, retrieved from https://www.dzp.pl/files/shares/Publikacje/Raport\%20Choroby $\% 20$ rzadkie $\% 20 \mathrm{dost} \% \mathrm{C} 4$ $\% 99$ pno $\%$ C5 $\% 9$ B $\%$ C4\%87\%20terpii $\% 20$ przegl $\%$ C4\%85d $\% 20$ polskich $\% 20$ rozwi $\%$ C4 $\% 85 z$ a $\%$ C5\%84\%20i\%20rekomendacje $\% 20 \mathrm{dla} \% 20$ Polski.pdf (30 June 2021).

e-CFR (n.d.) ORPHAN DRUGS ACT, retrieved from https://www.ecfr.gov/cgi-bin/textidx? $\mathrm{c}=\mathrm{ecfr} \& \mathrm{SID}=51 \mathrm{cf} 70689 \mathrm{~d} 51 \mathrm{f0ea} 4147 \mathrm{c} 0 \mathrm{a} 8 \mathrm{ac} 649321 \& \mathrm{rgn}=\mathrm{div} 5 \& \mathrm{view}=$ text\&node $=21: 5.0$ .1.1.6\&idno $=21$ (21 June 2021).

EJP RD (n.d.) Web content, retrieved from https://www.ejprarediseases.org/ (20 June 2021).

European Commission (n.d.), EU Research on rare diseases, retrieved from https://ec.europa.eu/info/research-and-innovation/research-area/health-research-andinnovation/rare-diseases_en (20 June 2021).

European Commission (2021) Medicines for children and rare diseases: Commission launches a public consultation, retrieved from https://ec.europa.eu/health/human-use/paediatricmedicines/20210510_news_en, 18 June 2021

European Medicines Agency (n.d.) Orphan designation: Overview, retrieved from https://www.ema.europa.eu/en/human-regulatory/overview/orphan-designation-overview (21 June 2021).

European Medicines Agency (n.d.) Cluster activities, retrieved from https://www.ema.europa.eu/en/partners-networks/international-activities/cluster-activities (17 June 2021).

European Medicines Agency (2020) European Commission, EMA and FDA agree new priorities to strengthen their collaboration on medicines, retrieved from https://www.ema.europa.eu/en/news/european-commission-ema-fda-agree-new-prioritiesstrengthen-their-collaboration-medicines (20 June 2021).

EUR-Lex, (n.d.) Regulation (EC) No 141/2000 of the European Parliament and of the Council of 16 December 1999 on orphan medicinal products, retrieved from https://eur-lex.europa.eu/legal-content/EN/TXT/?uri=CELEX:32000R0141, (21 June 2021). 
EUR-Lex, (n.d.) Regulation (EU) No 536/2014 of the European Parliament and of the Council of 16 April 2014 on clinical trials on medicinal products for human use, and repealing Directive 2001/20/EC, retrieved from

https://eur-lex.europa.eu/legal-content/EN/TXT/?uri=celex\%3A32014R0536 (21 June 2021).

EURORDIS (n.d.), Web content, retrieved from https://www.eurordis.org/ (20 June 2021).

Food and Drug Administration (2021) Rare Disease Day 2021: FDA Shows Sustained Support of Rare Disease Product Development During the Public Health Emergency, retrieved from https://www.fda.gov/news-events/fda-voices/rare-disease-day-2021-fda-shows-sustainedsupport-rare-disease-product-development-during-public (17 June 2021)

IRDiRC (n.d.) Web content, retrieved from https://irdirc.org/ (20 June 2021).

\section{References}

Afzali, A., Furtner, D., Melsheimer, R. \& Molloy, P.J. (2021) The Automatic Substitution of Biosimilars: Definitions of Interchangeability are not Interchangeable, Advances in Therapy, 38, pp. 20772093, doi: 10.1007/s12325-021-01688-9.

Athreye, S., Piscitello, L. \& Shadlen, K.C. (2020) Twenty-five years since TRIPS: Patent policy and international business, Journal of International Business Policy, 3, pp. 315-328, doi: 10.1057/s42214020-00079-1.

Bruce, F. (2021). Time Is Ripe For Global Action On Orphan Biosimilars, Generics Bulletin, retrieved from https://generics.pharmaintelligence.informa.com/GB150695/Time-Is-Ripe-ForGlobal-Action-On-Orphan-Biosimilars (11 August 2021).

Chan, A.Y.L. et al. (2020) Access and Unmet Needs of Orphan Drugs in 194 Countries and 6 Areas: A Global Policy Review with Content Analysis, Value in Health, 23(12), pp. 1580-1591, doi: 10.1016/j.jval.2020.06.020.

Chowdhury, S.F., Muktadir, Al Sium, S. \& Anwar, S. (2021) Research and Management of Rare Diseases in the COVID-19 Pandemic Era: Challenges and Countermeasures, Frontiers in Public Health, doi: 10.3389/fpubh.2021.640282.

Czech, M. et al. (2019) A Review of Rare Disease Policies and Orphan Drug Reimbursement Systems in 12 Eurasian Countries, Frontiers in Public Health, 7(146), doi: 10.3389/fpubh.2019.00416.

Day, S. et al. (2018) Recommendations for the design of small population clinical trials, Orphanet Journal of Rare Diseases, 13 (195), doi: 10.1186/s13023-018-0931-2.

Dowlat, H.A. (2016) The opportunities and challenges of biosimilar orphans, Expert Opinion on Orphan Drugs, 4(6), pp. 563-566, doi: 10.1517/21678707.2016.1171142.

EURORDIS (2020) How has COVID-19 impacted people with rare diseases? retrieved from: https://www.eurordis.org/publication/how-has-covid-19-impacted-people-rare-diseases (21 June 2021).

Gaasterland, C.M.W. et. al. (2019) The patient's view on rare disease trial design - a qualitative study, Orphanet Journal of Rare Diseases, 14(31), doi: 10.1186/s13023-019-1002-z.

Gelinas, L., Crawford, B., Kelman, A. \& Bierer, B. E. (2019) Relocation of study participants for rare and ultra-rare disease trials: Ethics and operations, Contemporary Clinical Trials, 84, doi: 10.1016/j.cct.2019.105812.

Gunne, E., McGarvey, C., Hamilton, K., Treacy, E., Lambert, D.M. \& Lynch, A L. (2020) A retrospective review of the contribution of rare diseases to paediatric mortality in Ireland, Orphanet Journal of Rare Diseases, 15(1), doi: 10.1186/s13023-020-01574-7.

IQVIA (2020) The Prospects for Biosimilars of Orphan Drugs in Europe, Current Landscape and Challenges Ahead, retrieved from https://www.iqvia.com/insights/the-iqviainstitute/reports/the-prospects-for-biosimilars-of-orphan-drugs-in-europe (15 June 2021).

Klimova, B., Storek, M., Valis, M. \& Kuca K. (2017) Global View on Rare Diseases: A Mini Review, Current Medicinal Chemistry, 24(29), pp. 3153-3158, doi: 10.2174/0929867324666170511111803. 
Kontoghiorghe, Ch.N., Andreou, N., Constantinou, K. \& Kontoghiorghes G.J. (2014) World health dilemmas: Orphan and rare diseases, orphan drugs and orphan patients, World Journal of Methodology, 4(3), pp. 163-188, doi: 10.5662/wjm.v4.i3.163.

Liu, Z., Zhu, L., Roberts, R. \& Tong, W. (2019) Toward Clinical Implementation of Next-Generation Sequencing-Based Genetic Testing in Rare Diseases: Where Are We?, Trends in genetics, 35(11), pp. 852-867, doi: 10.1016/j.tig.2019.08.006.

Maldonado, R., Jalil, S. \& Wartiovaara, K. (2021) Curative gene therapies for rare diseases, Journal of Community Genetics, 12, pp. 267-276, doi: https://doi.org/10.1007/s12687-020-00480-6.

Miller, K.L. \& Lanthier, M. (2018) Investigating the landscape of US orphan product approvals, Orphanet Journal of Rare Diseases, 13, doi: https://doi.org/10.1186/s13023-018-0930-3.

Moon, S. (2017) Powerful Ideas for Global Access to Medicines, The New England Journal of Medicine, 376, pp. 505-507, doi: 10.1056/NEJMp1613861.

National Organization for Rare Disorders (2021) Orphan Drugs in the United States: An Examination of Patents and Orphan Drug Exclusivity, retrieved from https://rarediseases.org/wpcontent/uploads/2021/03/NORD-Avalere-Report-2021_FNL-1.pdf, (30 June 2021).

Neelakandan, N., Venkatesh, D.N. \& Gomez, A.L. (2019) Orphan Drug Designation in Australia, Journal of Pharmaceutical Sciences and Research, 11(11), pp. 3592-3598, retrieved from: https://www.jpsr.pharmainfo.in/Documents/Volumes/vol11issue11/jpsr11111909.pdf (30 June 2021).

Richter, T., Nestler-Parr, S., Phil, M., Babela, R., Khan, Z.M., Tesoro, T., Molsen, E., \& Hughes, H.A. (2015) Rare Disease Terminology and Definitions-A Systematic Global Review: Report of the ISPOR Rare Disease Special Interest Group, Value in Health, 18(6), pp. 906-914, doi: 10.1016/j.jval.2015.05.008.

Sakushima, K., Takeda, H. \& Aoi, Y. (2021) Orphan drug designation and development in Japan: 25 years of experience and assessment, Nature, https://www.nature.com/articles/d41573-02100045-3

Sarpatwari, A., et. al, (2018) Evaluating the Impact of The Orphan Drug Act's Seven-Year Market Exclusivity Period, Health Affairs, 37(5), doi: 10.1377/hlthaff.2017.1179.

Schaefer, J., Lehne, M., Schepers, J., Prasser, F. \& Thun S. (2020) The use of machine learning in rare diseases: a scoping review, Orphanet Journal of Rare Diseases, 15(145), doi: 10.1186/s13023-02001424-6.

Slade, A., Isa, F., Kyte, D., Pankhurst, T., Kerecuk, L., Ferguson, J., Lipkin, G. \& Calvert, M. (2018) Patient reported outcome measures in rare diseases: a narrative review, Orphanet Journal of Rare Diseases, 13(61), doi: 10.1186/s13023-018-0810-x.

Stoller, J.K. (2018) The Challenge of Rare Diseases, Chest Journal, 153(6), pp. 1309-1314, doi: 10.1016/j.chest.2017.12.018.

Świerczyński, M. \& Więckowski, Z. (ed) (2019) Leczenie biologiczne a prawa pacjenta (Warszawa: Wolters Kluwer).

Świerczyński, M. \& Więckowski, Z. (2019a) Biosimilars and the Patent Law, Medicine, Law \& Society, 12(2), pp. 21-38, doi: 10.18690/mls.12.2.21-38.2019.

Świerczyński, M. \& Więckowski, Z. (ed) (2020) Model prawny leków biopodobnych, (Warszawa: Wydawnictwo Naukowe UKSW).

Teixeira, T., Kweder, S. L. \& Saint-Raymond, A. (2020) Are the European Medicines Agency, US Food and Drug Administration, and Other International Regulators Talking to Each Other? Clinical Pharmacology and Therapeutics, 107(3), pp. 507-513, doi: 10.1002/cpt.1617.

World Health Organization (2018). Technical report: pricing of cancer medicines and its impacts: a comprehensive technical report for the World Health Assembly Resolution 70.12: operative paragraph 2.9 on pricing approaches and their impacts on availability and affordability of medicines for the prevention and treatment of cancer (World Health Organization), retrieved from: https:/ /apps.who.int/iris/handle/10665/277190 (30 June 2021).

Workman, P., Draetta, G.F., Schellens, J. \& Bernards, R. (2017) How Much Longer Will We Put Up With \$100,000 Cancer Drugs?, Cell, 168, pp. 579-583, doi: 10.1016/j.cell.2017.01.034. 
